Article

\title{
Effects of Annealing Temperature on Properties of Ti-Ga-Doped ZnO Films Deposited on Flexible Substrates
}

\author{
Tao-Hsing Chen * and Ting-You Chen \\ Department of Mechanical Engineering, National Kaohsiung University of Applied Sciences, \\ Kaohsiung City 807, Taiwan; E-Mail: stars@pchome.com.tw
}

* Author to whom correspondence should be addressed; E-Mail: thchen@cc.kuas.edu.tw; Tel.: +886-7-381-4526 (ext. 5330); Fax: +886-7-383-1373.

Academic Editors: Ming-Tsang Lee and Thomas Nann

Received: 8 October 2015 / Accepted: 29 October 2015 / Published: 3 November 2015

\begin{abstract}
An investigation is performed into the optical, electrical, and microstructural properties of Ti-Ga-doped $\mathrm{ZnO}$ films deposited on polyimide (PI) flexible substrates and then annealed at temperatures of $300{ }^{\circ} \mathrm{C}, 400{ }^{\circ} \mathrm{C}$, and $450{ }^{\circ} \mathrm{C}$, respectively. The X-ray diffraction (XRD) analysis results show that all of the films have a strong (002) Ga doped $\mathrm{ZnO}(\mathrm{GZO})$ preferential orientation. As the annealing temperature is increased to $400{ }^{\circ} \mathrm{C}$, the optical transmittance increases and the electrical resistivity decreases. However, as the temperature is further increased to $450{ }^{\circ} \mathrm{C}$, the transmittance reduces and the resistivity increases due to a carbonization of the PI substrate. Finally, the crystallinity of the $\mathrm{ZnO}$ film improves with an increasing annealing temperature only up to $400{ }^{\circ} \mathrm{C}$ and is accompanied by a smaller crystallite size and a lower surface roughness.
\end{abstract}

Keywords: annealing temperature effect; Ti-Ga; flexible substrate; polyimide

\section{Introduction}

Transparent conducting thin films deposited on glass substrates are widely used throughout the semiconductor and electronics industries. However, glass is heavy and brittle, and is thus unsuitable for emerging flexible electronic devices, such as smart cards, electronic maps, flat panel displays, and so on [1,2]. Consequently, the feasibility of utilizing polymer materials as a substrate material has attracted increasing interest in recent years $[3,4]$. Among the various conducting thin film materials available, $\mathrm{ZnO}$, doped with elements such as $\mathrm{Al}$ [5], Ga [6], In [7], and Mo [8], has received particular 
attention due to its excellent optical and electrical properties. Ti-Ga co-doped $\mathrm{ZnO}$ thin films on glass substrates have also been widely investigated in recent years due to their high visible transparency and electrical conductivity [9,10]. However, the properties of Ti-Ga-doped $\mathrm{ZnO}$ films on flexible substrates have attracted little interest in the literature thus far.

Various methods exist for the deposition of thin-film structures on glass or polymer substrates, including spray pyrolysis [11], chemical vapor deposition [12], sol-gel processing [13], and sputtering [14]. Many studies have shown that films deposited using radio-frequency (RF) magnetron sputtering have good crystallinity and microstructural uniformity even at low substrate temperatures [9,15-17]. However, the microstructure and properties (optical and electrical) of these films vary significantly with the discharge power, working gas pressure, distance between the target and substrate, and post-deposition annealing temperature.

Accordingly, in the present study, Ti-Ga-doped $\mathrm{ZnO}$ films are deposited on polyimide (PI) substrates using the RF magnetron sputtering method. The optical, electrical, and microstructural properties of the films are then investigated following annealing at temperatures of $300{ }^{\circ} \mathrm{C}, 400{ }^{\circ} \mathrm{C}$, and $450^{\circ} \mathrm{C}$, respectively.

\section{Experimental Procedure}

Ti-Ga-doped $\mathrm{ZnO}$ thin films were deposited on PI substrates with dimensions of $2.0 \mathrm{~cm} \times 4.0 \mathrm{~cm} \times$ $200 \mu \mathrm{m}$. The RF sputtering system consisted of a Ga:ZnO alloy target with a RF power supply and a $\mathrm{Ti}$ metallic target (purity 99.999\%) with a Directly Current (DC) power supply. Both targets measured 2 inches by $0.50 \mathrm{~cm}$ (diameter $\times$ thickness). The Ga:ZnO target was sintered from Ga doped $\mathrm{ZnO}$ (GZO) pellets containing $\mathrm{ZnO}$ (purity 99.2\%) doped with $3 \% \mathrm{Ga}_{2} \mathrm{O}_{3}$ (99.9\%). Prior to sputtering, the substrates were cleaned in acetone and methanol in an ultrasonic bath and then dried under a nitrogen gas flow. In the sputtering process, the distance between the targets and the substrate was fixed at $6 \mathrm{~cm}$ and the flow rate and pressure of the Argon working gas were set as $15 \mathrm{~cm}^{3} / \mathrm{min}$ and $1.33 \times 10^{-3} \mathrm{~Pa}$, respectively. The sputtering process commenced by depositing a GZO film on the PI substrate using a sputtering power and deposition rate of $100 \mathrm{~W}$ and $3.33 \mathrm{~nm} / \mathrm{min}$, respectively. A thin Ti layer was then sputtered on the GZO film with a sputtering power of $60 \mathrm{~W}$ and a deposition rate of $0.85 \mathrm{~nm} / \mathrm{min}$. The as-deposited specimens were then annealed for $20 \mathrm{~min}$ in a vacuum annealing furnace at temperatures of $300{ }^{\circ} \mathrm{C}, 400{ }^{\circ} \mathrm{C}$, and $450{ }^{\circ} \mathrm{C}$, respectively.

The microstructural characteristics of the as-sputtered and annealed films were investigated by X-ray diffraction (XRD, SIEMENS D5000). In addition, the electrical resistivity was evaluated using a Hall Effect measurement system (AHM-800B). The transmittance spectra were measured at wavelengths of 300 800 nm using a UV-VIS spectrophotometer (Hitachi U-4001). Finally, the surface morphology was examined using a scanning electron microscope (SEM, Philip's XL-40 FEG) and an atomic force microscope (AFM) operated in a contact mode. 


\section{Results and Discussions}

\subsection{Thickness and Structural Analysis of Ti-Ga-Doped ZnO Films}

The thickness of the GZO and Ti layers was calculated based on the deposition time (30 min) and deposition rate. The thickness of the GZO layer was found to vary between 100 and $120 \mathrm{~nm}$, while that of the Ti layer varied between 50 and $60 \mathrm{~nm}$. The chemical composition of the as-deposited Ti-Ga-doped $\mathrm{ZnO}$ film was examined by means of energy dispersive X-ray (EDX) spectroscopy. As expected, the film consists mainly of $\mathrm{Zn}, \mathrm{Ga}$, and Ti elements (Figure 1).

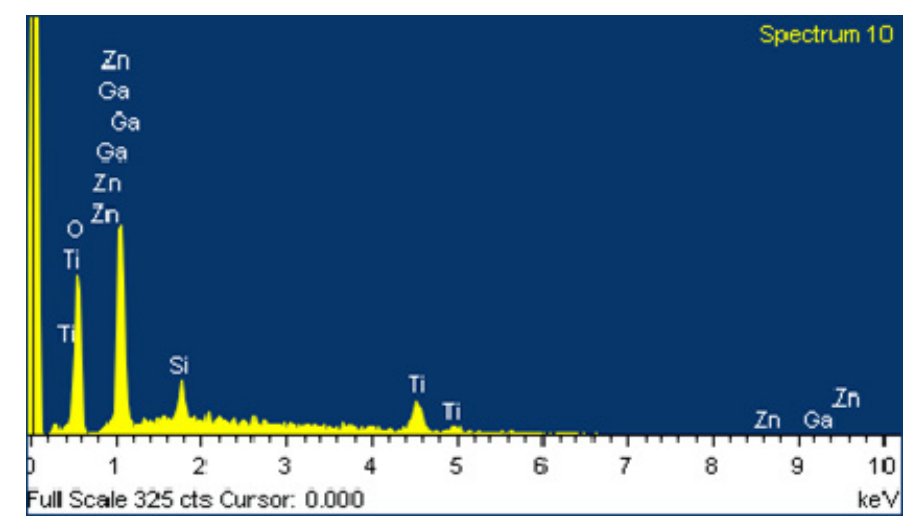

Figure 1. Energy dispersive X-ray (EDX) analysis results for as-deposited Ti-Ga-doped ZnO film.

Figure 2a shows the XRD spectra of the as-deposited and annealed Ti-Ga-doped $\mathrm{ZnO}$ films. It is seen that all the films have a strong diffraction peak located at around $2 \theta=34.3^{\circ}$. The position of this peak is consistent with that of standard $\mathrm{ZnO}$ crystal $\left(34.45^{\circ}\right)$. Hence, it is inferred that the GZO thin films have the structural characteristics of hexagonal $\mathrm{ZnO}$ wurtzite. The absence of $\mathrm{Ga}$ and Ti peaks in the XRD scans suggests that Ga and Ti are present only in very small quantities and are confined to the non-crystalline region of the annealed films at the grain boundaries [18-20]. It is observed that the intensity of the diffraction peak increases as the annealing temperature is increased to $400{ }^{\circ} \mathrm{C}$, but decreases as the temperature is further increased to $450{ }^{\circ} \mathrm{C}$. In other words, the microstructure of the Ti-Ga-doped $\mathrm{ZnO}$ films becomes increasingly crystalline under higher temperatures (at $400{ }^{\circ} \mathrm{C}$ ). Figure $2 \mathrm{~b}$ shows the full width at half maximum (FWHM) values of the as-deposited and annealed Ti-Ga-doped $\mathrm{ZnO}$ films. It is seen that the FWHM decreases as the annealing temperature increases from 300 to $400{ }^{\circ} \mathrm{C}$, but increases at the highest annealing temperature of $450{ }^{\circ} \mathrm{C}$. In other words, the maximum crystallinity occurs in the film annealed at $400{ }^{\circ} \mathrm{C}$. Compared to Ti co-doped GZO films deposited on glass substrates [21], the diffraction peak intensity of the present films is rather weak. Moreover, the FWHM values are somewhat larger. 

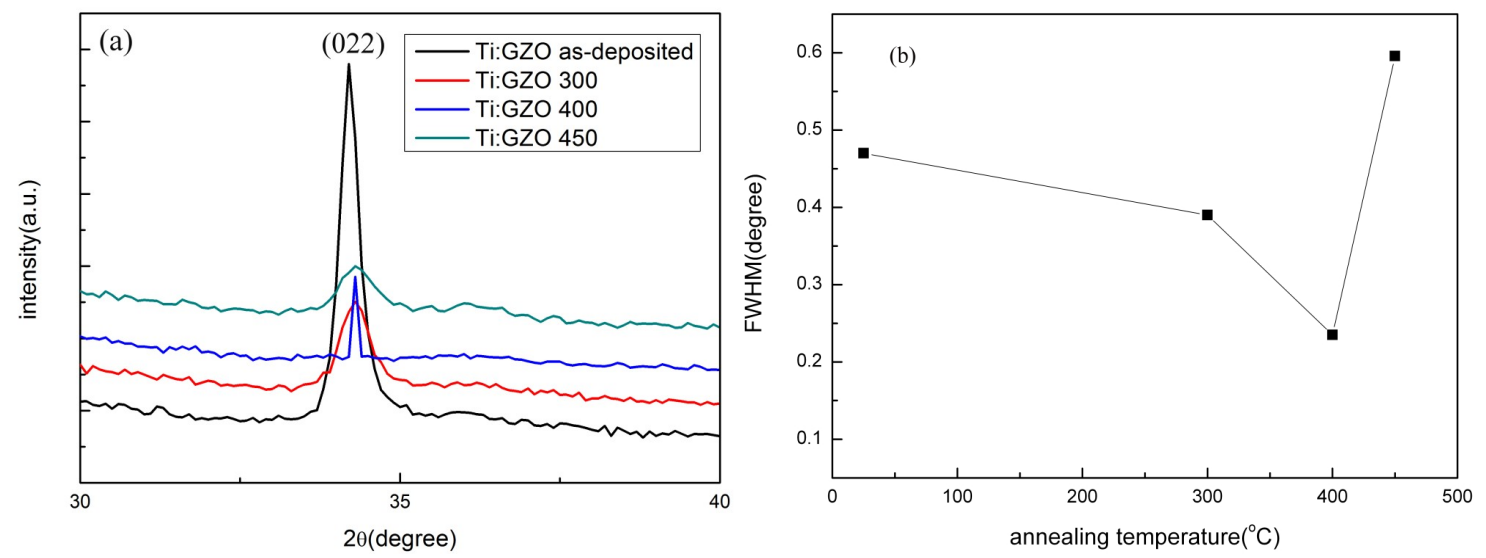

Figure 2. (a) X-ray diffraction (XRD) patterns; (b) Full width at half maximum (FWHM) values of as-deposited and annealed $\mathrm{Ti}-\mathrm{Ga}$-doped $\mathrm{ZnO}$ thin films as a function of annealing temperature.

\subsection{Optical and Electrical Properties of Ti-Ga-Doped ZnO Films}

Figure 3 shows the transmission spectra of the as-deposited and annealed Ti-Ga-doped $\mathrm{ZnO}$ films over the wavelength range of $300-800 \mathrm{~nm}$. It is seen that the as-deposited film has a low transparency of just $60 \%$ in the visible region and has a sharp absorption edge at $\sim 380 \mathrm{~nm}$. For the annealed $\mathrm{ZnO}$ films, the transmittance increases to approximately $80 \%$ as the annealing temperature is increased from $300-400{ }^{\circ} \mathrm{C}$. In other words, the transformation of the $\mathrm{ZnO}$ film to a crystalline structure prompts an improvement in the optical transmittance. However, at a higher temperature of $450{ }^{\circ} \mathrm{C}$, the transmittance reduces to around $75 \%$. The PI substrate has a maximum endurance temperature of approximately $\sim 500{ }^{\circ} \mathrm{C}$. Thus, it is speculated that the reduced optical transmittance of the $\mathrm{ZnO}$ film at higher annealing temperatures is due to thermally induced carbonization of the underlying PI substrate.

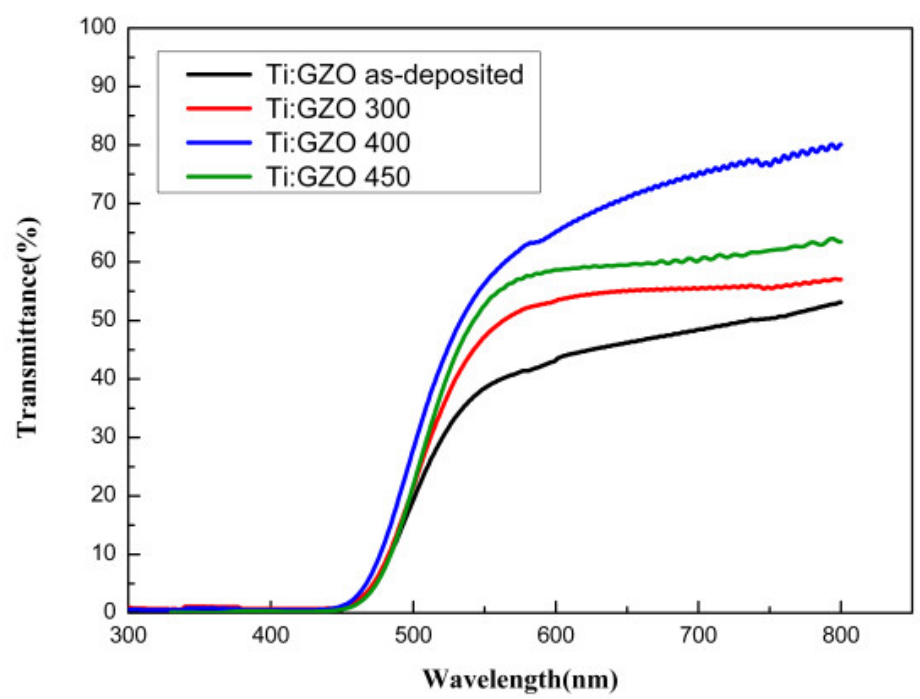

Figure 3. Optical transmittance of as-deposited and annealed Ti-Ga-doped $\mathrm{ZnO}$ thin films.

Figure $4 \mathrm{a}-\mathrm{c}$ show the resistivity, carrier concentration, and Hall mobility properties of the as-deposited and annealed films. As shown in Figure 4a, the resistivity reduces from $4 \times 10^{-3}$ to $2.2 \times 10^{-3} \Omega$-cm 
as the annealing temperature increases from 25 to $400{ }^{\circ} \mathrm{C}$. The lower resistivity stems from the improved crystallinity of the Ti-Ga $\mathrm{ZnO}$ film structure, a lower scattering of the charge carriers at the grain boundary, the increased substitutional doping, and a reduction in the number of interstitial atoms. The reduced resistivity also suggests an improved diffusion of the Ti atoms into the Ga-doped $\mathrm{ZnO}$ film under higher temperatures. For the specimen annealed at the highest temperature of $450{ }^{\circ} \mathrm{C}$, the resistivity increases to approximately $7.9 \times 10^{-3} \Omega-\mathrm{cm}$. The increased resistivity can be attributed to the carbonization of the PI substrate. Figure 4b,c shows that the carrier concentration and Hall mobility increase as the annealing temperature increases from 25 to $400{ }^{\circ} \mathrm{C}$. In other words, a higher annealing temperature prompts a greater number of free carrier electrons and improves the conductivity. However, both properties reduce at a higher annealing temperature of $450{ }^{\circ} \mathrm{C}$ due to carbonization of the PI layer.

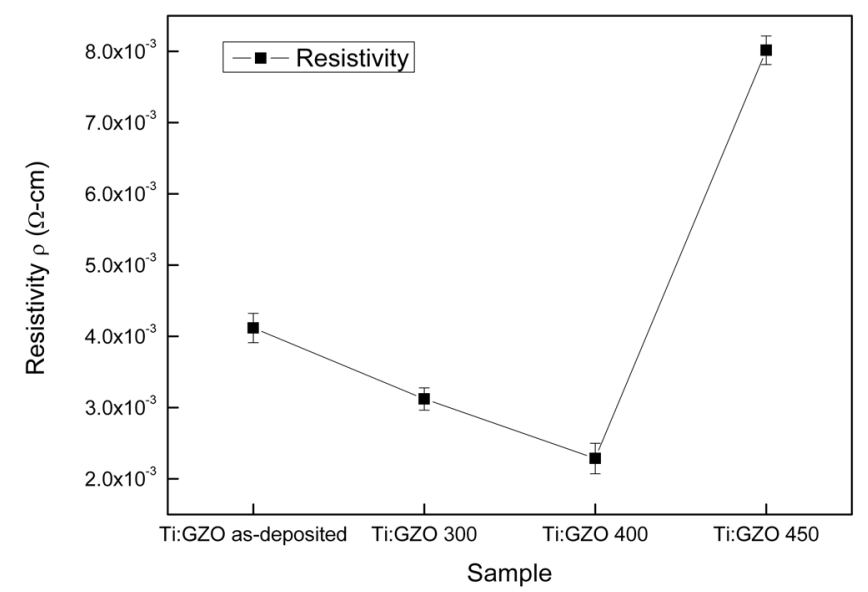

(a)

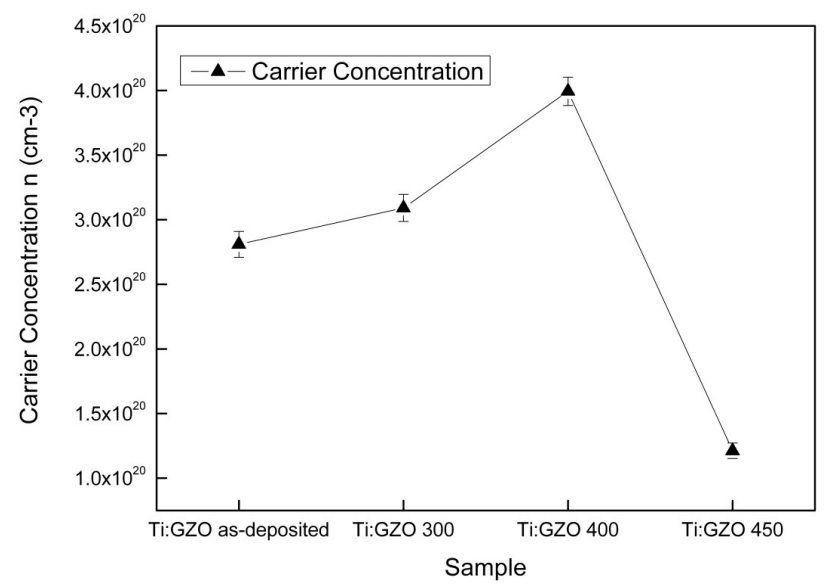

(b)

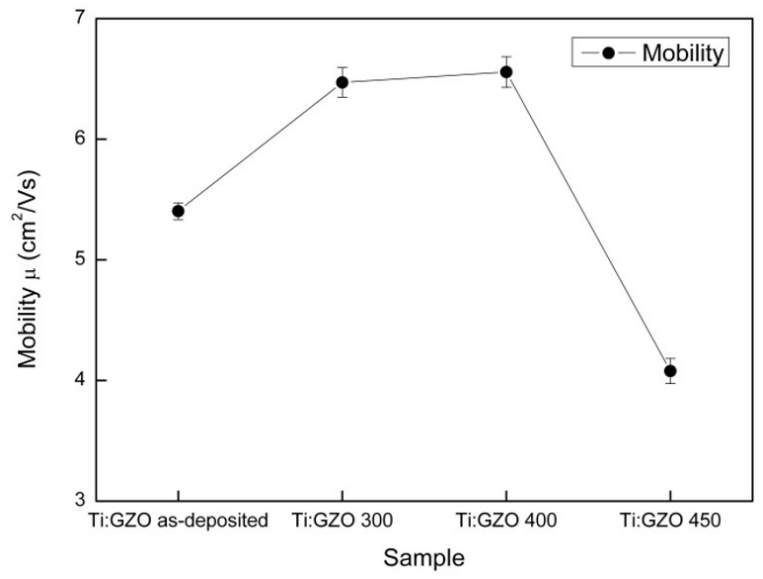

(c)

Figure 4. (a) Resistivity; (b) Carrier concentration; and (c) Hall mobility of as-deposited and annealed Ti-Ga-doped $\mathrm{ZnO}$ thin films.

\subsection{AFM and SEM Surface Observations}

Figure 5a-d show the AFM morphologies of the as-deposited and annealed Ti-Ga-doped $\mathrm{ZnO}$ films. The images show that the crystallinity of the films improves with an increasing annealing temperature up to $400{ }^{\circ} \mathrm{C}$ and is accompanied by a smaller crystallite size. The smaller crystallite size leads to an improved smoothness due to the formation of a more dense surface morphology. 


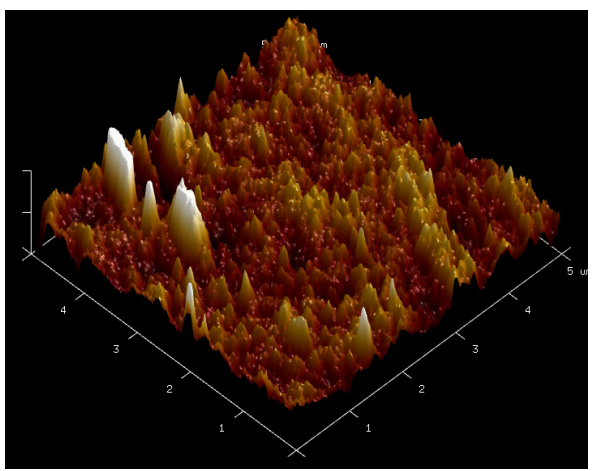

(a)

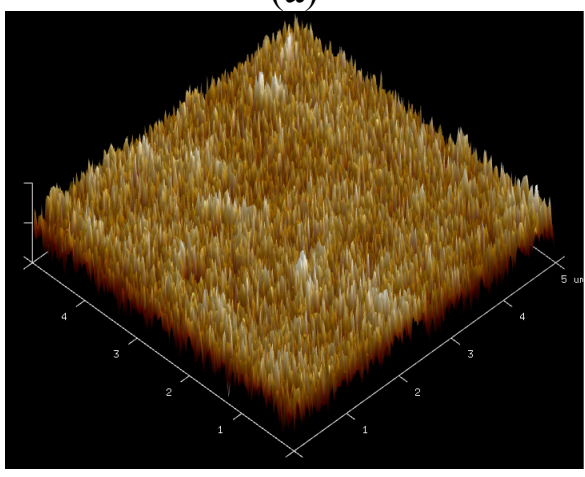

(c)

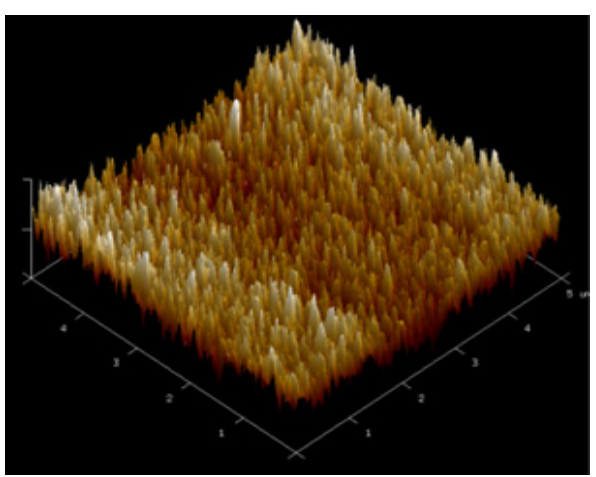

(b)

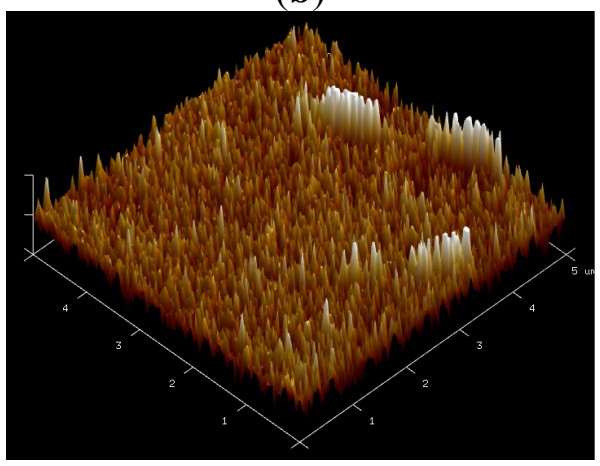

(d)

Figure 5. Three-dimensional (3D) atomic force microscope (AFM) images of Ti-Ga-doped $\mathrm{ZnO}$ thin films in (a) as-deposited condition; and following annealing at: (b) $300{ }^{\circ} \mathrm{C}$; (c) $400{ }^{\circ} \mathrm{C}$; and (d) $450{ }^{\circ} \mathrm{C}$.

Figure $6 \mathrm{a}-\mathrm{d}$ present SEM images of the various Ti-Ga-doped $\mathrm{ZnO}$ films. The surface morphology of the as-deposited film has a pebble-like appearance with an average grain size of around $70 \mathrm{~nm}$ (Figure 6a). However, an inspection of Figure $6 \mathrm{~b}-\mathrm{d}$ shows that the average grain size decreases to approximately $30 \mathrm{~nm}$ as the annealing temperature is increased to $450{ }^{\circ} \mathrm{C}$. This finding is to be expected since a higher annealing temperature increases the average energy of the bombarding ions on the growing film, thereby enhancing the atom mobility on the surface. Moreover, an increasing annealing temperature also increases the diffusion rate, thereby allowing a more perfect Ti-Ga-doped $\mathrm{ZnO}$ film crystal to be obtained.

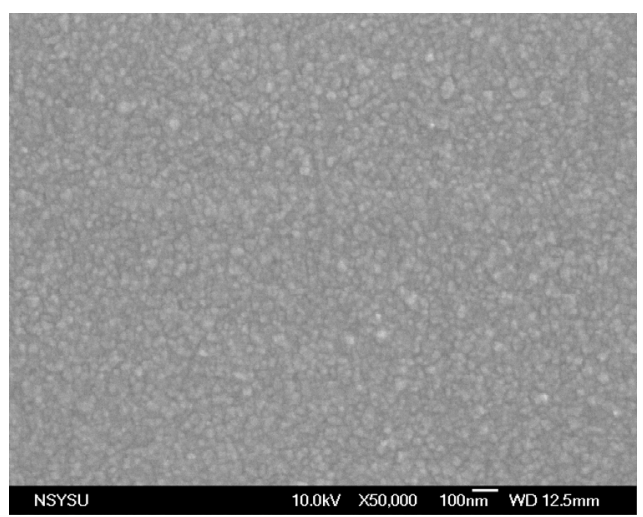

(a)

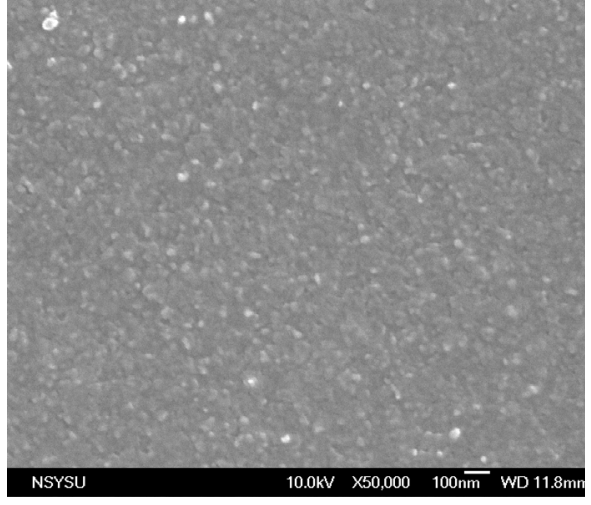

(b)

Figure 6. Cont. 


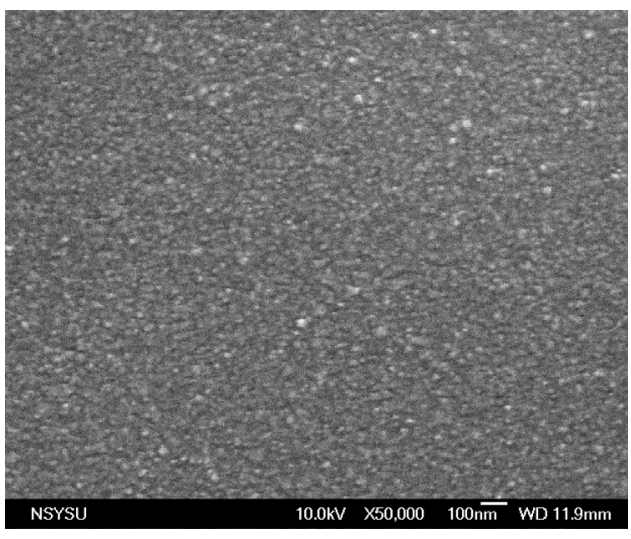

(c)

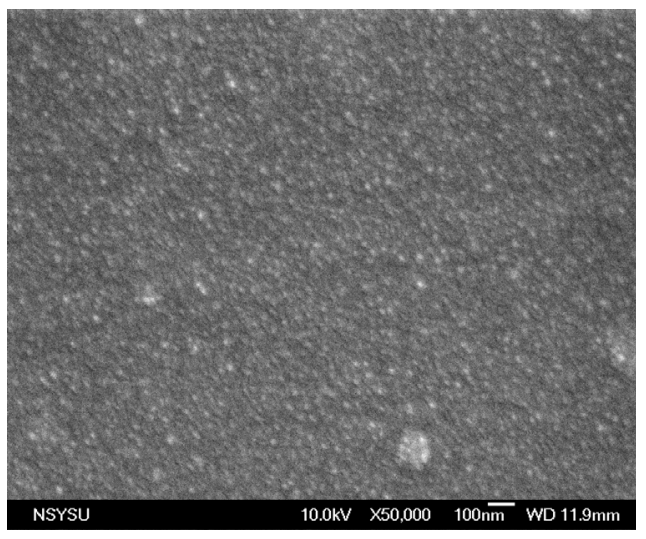

(d)

Figure 6. Scanning electron microscope (SEM) images of Ti-Ga-doped $\mathrm{ZnO}$ films in (a) as-deposited condition; and following annealing at: (b) $300{ }^{\circ} \mathrm{C}$; (c) $400{ }^{\circ} \mathrm{C}$; and (d) $450{ }^{\circ} \mathrm{C}$.

\section{Conclusions}

This study has investigated the effects of the annealing temperature $\left(300 \sim 450{ }^{\circ} \mathrm{C}\right)$ on the optical, electrical, and microstructural properties of Ti-Ga-doped $\mathrm{ZnO}$ films deposited on PI flexible substrates. The XRD analysis results have shown that the as-deposited and annealed films have a hexagonal structure with a preferred orientation of the c-axis perpendicular to the substrate. The transmittance of the $\mathrm{ZnO}$ films increases to approximately $80 \%$ as the annealing temperature is increased from $300 \sim 400{ }^{\circ} \mathrm{C}$ due to an improved crystallinity of the $\mathrm{ZnO}$ microstructure. However, the transmittance reduces to $75 \%$ as the annealing temperature is further increased to $450{ }^{\circ} \mathrm{C}$ due to a carbonization of the PI substrate. The electrical resistivity of the $\mathrm{ZnO}$ films falls to a minimum value of approximately $2.2 \times 10^{-3} \Omega$-cm at an annealing temperature of $400{ }^{\circ} \mathrm{C}$. However, the resistivity, carrier concentration, and Hall mobility are all degraded at a higher annealing temperature of $450{ }^{\circ} \mathrm{C}$ due to substrate damage. The AFM and SEM surface observations have shown that a higher annealing temperature prompts an improved crystallinity of the doped $\mathrm{ZnO}$ microstructure, a smaller grain size, and a reduced surface roughness. In general, the quality of the Ti-Ga-doped $\mathrm{ZnO}$ films deposited on PI substrates is somewhat poorer than that of equivalent films deposited on glass substrates. However, the present results suggest that given an appropriate control of the post-deposition annealing temperature, Ti-Ga-doped $\mathrm{ZnO}$ films deposited on PI substrates represent a feasible solution for emerging flexible electronics applications.

\section{Acknowledgments}

The authors gratefully acknowledge the financial support provided to this study by the National Science Council (NSC) of Taiwan under Contract No. NSC 102-2212-E-151-006-MY3.

\section{Author Contributions}

All the authors contributed to the paper. Tao-Hsing Chen was involved in writing and designing the aim of this manuscript. Ting-You Chen did the experiment. Tao-Hsing Chen designed the scope of the paper. Tao-Hsing Chen discussed the conclusions and reviewed the manuscript. 


\section{Conflicts of Interest}

The authors declare no conflict of interest.

\section{References}

1. Berry, J.J.; Ginley, D.S.; Burrows, P.E. Organic light emitting diodes using a Ga:ZnO anode. Appl. Phys. Lett. 2008, 92, 193304.

2. Wang, Y.G.; Lau, S.P.; Zhang, X.H.; Hng, H.H.; Lee, H.W.; Yu, S.F.; Tay, B.K. Enhancement of near-band-edge photoluminescence from $\mathrm{ZnO}$ films by face-to-face annealing. J. Cryst. Growth 2003, 259, 335-342.

3. Jung, Y.S.; Kim, K.H. Effects of intermediate metal layer on the properties of Ga-Al doped $\mathrm{ZnO} / \mathrm{metal} / \mathrm{Ga}-\mathrm{Al}$ doped $\mathrm{ZnO}$ multilayers deposited on polymer substrate. Mater. Res. Bull. 2012, 47, 2895-2897.

4. Lin, Y.C.; Li, J.Y.; Yen, W.T. Low temperature ITO thin film deposition on PES substrate using pulse magnetron sputtering. Appl. Surf. Sci. 2008, 24, 3262-3268.

5. Rim, Y.S.; Kim, S.M.; Choi, H.W.; Park, S.J.; Kim, K.H. Preparation of Al-doped ZnO thin film deposited at room temperature. Colloids Surf. A 2008, 313-314, 461-464.

6. Park, S.M.; Ikegami, T.; Ebihara, K. Effects of substrate temperature on the properties of Gadoped $\mathrm{ZnO}$ by pulsed laser deposition. Thin Solid Films 2006, 513, 90-94.

7. Kim, S.M.; Park, S.J.; Yoon, H.H.; Choi, H.W.; Kim, K.H. Preparation of ITO and IZO thin films by using the facing targets sputtering (FTS) method. J. Korean Phys. Soc. 2009, 55, 1996-2001.

8. Hsieh, P.T.; Chen, T.H.; Huang, C.Y.; Wang, J.Q.; Chuang, R.W. Molybdenum-doped Zinc Oxide Nanocomposite Film on glass derived by Sputering Technique. J. Micro/Nanolithogr. MEMS MOEMS 2010, 9, doi:10.1117/1.3514706.

9. Park, T.Y.; Choi, Y.S.; Kang, J.W.; Jeong, J.H.; Park, S.J.; Jeon, D.M.; Kim, J.W.; Kim, Y.C. Enhanced optical power and low forward voltage of GaN-based light-emitting diodes with Ga-doped ZnO transparent conducting layer. Appl. Phys. Lett. 2010, 96, 051124.

10. Zhang, D.H.; Yang, T.L.; Ma, J.; Wang, Q.P.; Gao, R.W.; Ma, H.L. Preparation of transparent conducting ZnO:Al films on polymer substrates by r. f. magnetron sputtering. Appl. Surf. Sci. 2000, 158, 43-48.

11. Manifacier, J.C.; Szepersy, L.; Bresse, J.F.; Perotin, M.; Stuck, R. $\mathrm{In}_{2} \mathrm{O}_{3}:(\mathrm{Sn})$ and $\mathrm{SnO}_{2}:(\mathrm{F})$ films - Application to solar energy conversion; part 1-Preparation and characterization. Mater. Res. Bull. 1978, 14, 109-119.

12. Wenas, W.W.; Yamada, A.; Takahashi, K.; Yoshino, M.; Konagai, M. Electrical and optical properties of boron-doped $\mathrm{ZnO}$ thin films for solar cells grown by metalorganic chemical vapor deposition. J. Appl. Phys. 1991, 70, 7119-7123.

13. Natsume, Y.; Sakata, H. Zinc oxide films prepared by sol-gel spin-coating. Thin Solid Films 2000, 372, 30-36.

14. Chiou, B.S.; Hsieh, S.T. Rf magnetron-sputtered indium tin oxide film on a reactively ion-etched acrylic substrate. Thin Solid Films 1993, 229, 146-155. 
15. Sheng, H.; Emanetoglu, N.W.; Muthukumar, S.; Yakshinskiy, B.V.; Feng, S.; Lu, Y. Ta/Au ohmic contacts to n-type ZnO. J. Electron. Mater. 2003, 32, 935-938.

16. Ryu, Y.R.; Zhu, S.; Look, D.C.; Wrobel, J.M.; Jeong, H.M.; White, H.W. Synthesis of p-type ZnO films. J. Cryst. Growth 2000, 216, 330-334.

17. Yamamoto, S.; Yamanaka, T.; Ueda, Z. Properties of $\mathrm{Sn}$-doped $\mathrm{In}_{2} \mathrm{O}_{3}$ by reactive magnetron sputtering and subsequent annealing. J. Vac. Sci. Technol. 1987, A5, 1952.

18. Tseng, J.Y.; Chen, Y.T.; Yang, M.Y.; Wang, C.Y.; Li, P.C.; Yu, W.C.; Hsu, Y.F.; Wang, S.F. Deposition of low-resistivity gallium-doped zinc oxide films by low-temperature radio-frequency magnetron sputtering. Thin Solid Films 2009, 517, 6310-6314.

19. Ma, J.; Zhang, D.H.; Zhang, J.Q.; Tan, C.Y.; Yang, T.L.; Ma, H.L. Preparation and characterization of ITO films deposited on polyimide by reactive evaporation at low temperature. Appl. Surf. Sci. 1999, 151, 239-243.

20. Paul, G.K.; Sen, S.K. Sol-gel preparation, characterization and studies on electrical and thermoelectrical properties of gallium doped zinc oxide films. Mater. Lett. 2002, 57, 742-746.

21. Chen, T.H.; Liao, T.Y. Influence of Annealing Temperature on the Characteristics Ti co-doped GZO Thin Solid Film. J. Nanomater. 2003, 2003, doi:10.1155/2013/502382.

(C) 2015 by the authors; licensee MDPI, Basel, Switzerland. This article is an open access article distributed under the terms and conditions of the Creative Commons Attribution license (http://creativecommons.org/licenses/by/4.0/). 